\title{
Política Monetária e Preços de Ativos no Brasil: uma Avaliação Empírica para o Período de Metas para a Inflação
}

\section{Monetary Policy and Asset Prices in Brazil: an Empirical Evaluation for the Period of Inflation Targetin}

\author{
Edilean Kleber da Silva Bejarano Aragón* \\ Bruno Tadeu Lopes Siqueira de Moura** \\ Klebson Humberto de Lucena Moura***
}

\begin{abstract}
Resumo: Este artigo investiga a reação da política monetária do Banco Central do Brasil (BCB) às oscilações nos preços das ações e na taxa de câmbio no período de metas de inflação. Em adição, verifica-se se a taxa Selic tem respondido de forma assimétrica aos desvios positivos e negativos do hiato dos preços dos ativos. Para isso, diferentes especificações da função de reação forward-looking do BCB são estimadas pelo Método Generalizado dos Momentos. Os resultados mostram que, no curto prazo, o BCB tem respondido de forma simétrica aos hiatos positivos e negativos da taxa de câmbio, mas não tem reagido ao hiato do preço das ações. Em adição, as estimativas dos parâmetros implícitos da função de reação indicam que apenas a resposta de longo prazo da taxa Selic ao hiato da inflação esperada é significativa. Isso está em conformidade com a visão teórica de que a autoridade monetária deve responder apenas indiretamente aos preços dos ativos, na medida em que esses preços sinalizem alterações na inflação esperada.
\end{abstract}

Palavras-chave: Política monetária. Função de reação Forward-looking. Preços de ativos. Brasil.

Abstract: This paper investigates the reaction of the Central Bank of Brazil (CBB)'s monetary policy to stock and exchange rate price movements during the inflationtargeting period. In addition, it verifies whether the Selic rate has responded asymmetrically to the positive and negative deviations of asset price gaps. Therefore, different specifications of the CBB's forward-looking reaction function are estimated by the Generalized Method of Moments. Results show that, in the short term, the CBB has responded asymmetrically to positive and negative exchange rate gaps, but that it has not reacted to stock price gaps. Moreover, the estimates of the implicit parameters of the reaction function indicate that only the long-term response of the Selic rate to expected inflation gap is significant. This is consistent with the theoretical analysis that the monetary authority should respond only indirectly to asset prices whenever such prices indicate changes in expected inflation.

Keywords: Monetary policy. Forward-looking. Reaction function. Asset prices. Brazil.

* Professor do Programa de Pós-graduação em Economia (PPGE) da Universidade Federal da Paraíba (UFPB). Doutor em Economia Aplicada pela Universidade Federal do Rio Grande do Sul. E-mail: edilean@hotmail.com

** Mestre em Economia pelo PPGE/UFPB. E-mail: brunotlmoura@hotmail.com

*** Doutorando em Economia pelo PIMES/Universidade Federal de Pernambuco (UFPE). E-mail: klebson.moura@gmail.com 
JEL Classification: E52; E61.

\section{Introdução}

Uma importante preocupação dos formuladores de políticas econômicas diz respeito aos efeitos de instabilidades financeiras e volatilidade nos preços dos ativos (tais como preços das ações, de imóveis e taxa de câmbio) sobre a atividade econômica. Borio, Kennedy e Prowse (1994) mostram que quedas nos preços de ações e imóveis estão associadas às reduções no produto real em diversos países. Por sua vez, Borio e Lowe (2002) argumentam que movimentos no médio e longo prazo nos preços dos títulos do governo e na taxa de câmbio são acompanhados de situações de disseminação de instabilidades financeiras, levando a problemas do lado real da economia. Os casos reais mais recentes são os crashes das bolsas da Ásia e da América Latina na década de 1990, o estouro da bolha da Nasdaq em 2000 e a crise financeira de 2007-2009 nos Estados Unidos, que estiveram diretamente relacionados ao fraco desempenho dessas economias nesses períodos.

São vários os mecanismos pelos quais oscilações nos preços dos ativos podem afetar a economia. Por exemplo, um aumento nos preços das ações e habitações pode elevar a riqueza e, consequentemente, o consumo agregado das famílias. Em adição, os efeitos positivos de uma elevação nos preços dos ativos sobre os colaterais e balanços das famílias, firmas e intermediários financeiros podem aumentar o fluxo de crédito da economia, os gastos privados com consumo e investimento, o produto agregado e a taxa de inflação. Por sua vez, uma alteração na taxa de câmbio pode afetar a inflação e a atividade econômica através de seus efeitos sobre os preços dos bens comercializáveis, exportações líquidas e, consequentemente, a demanda agregada da economia.

Em razão dos efeitos econômicos dos preços dos ativos, uma vasta literatura tem discutido se os bancos centrais devem responder diretamente às mudanças nesses preços. Cecchetti (2000) e Cecchetti, Genberg e Wadhwani (2003) argumentam que bolhas no mercado de ativos podem criar distorções no investimento e consumo agregado, levando a excessivos aumentos e quedas no produto e inflação. Nesse caso, o banco central pode reforçar a estabilidade econômica se ele reagir diretamente aos desalinhamentos nos preços dos ativos. Borio e Lowe (2002) e Bordo e Jeanne (2002) destacam que a resposta da política monetária ao mercado de ativos pode ajudar a preservar a estabilidade financeira e monetária. ${ }^{1}$ Com relação à taxa de câmbio, Hausmann, Ugo e Ernesto (2001) e Calvo e Reinhart (2002) destacam que os efeitos sobre os balanços dos agentes econômicos tem sido a principal razão de por que bancos centrais procuram evitar desvalori-

$1 \quad$ Akram, Gunnar e Eitrheim (2006) e Kannan, Rabanal e Scott (2012) também observam que a inclusão dos preços das habitações na regra de política monetária aperfeiçoa a estabilidade econômica. 
zações cambiais quando há choques externos. Aizenman, Hutchison e Noy (2011) verificam que um elevado peso sobre a volatilidade cambial na função perda do banco central pode trazer ganhos de bem-estar, principalmente em economias emergentes.

Em contraposição, Bernanke e Gertler (1999, 2001) e Mishkin (2007, 2008) defendem que a autoridade monetária deve responder apenas indiretamente aos preços dos ativos, na medida em que esses preços sinalizem mudanças na inflação esperada, produto e emprego. Visto que os preços dos ativos são bastante voláteis e desalinhamentos desses preços são difíceis de identificar, uma resposta ativa da política monetária pode desestabilizar a economia. Assim, a visão tradicional, denominada por Issing $(2009,2011)$ de "Jackson Hole Consensus", recomenda que bancos centrais não tentem estourar bolhas reagindo a booms nos preços dos ativos, mas atuem após a explosão dessas bolhas.

Dentro dessa temática, duas questões empíricas têm emergido, a saber: 1) bancos centrais têm respondido aos preços dos ativos? 2) essa resposta tem sido assimétrica, isto é, o instrumento de política monetária tem respondido de forma diferente a busts e booms nos preços dos ativos? Vários trabalhos têm procurado responder essas questões. Por exemplo, Rigobon e Sack (2003), Dupor e Conley (2004) e Björland e Leitemo (2009) encontram evidências de que o Federal Reserve (Fed) responde aos preços das ações, enquanto Fuhrer e Tootell (2008) e Hayford e Malliaris (2005) mostram que a reação da política monetária a esses preços não é evidente. Botzen e Marey (2010) verificam que a política monetária do Banco Central Europeu (BCE) reagiu ao mercado de ações no período anterior à crise financeira internacional de 2008. Clarida, Galí e Gertler (1998) encontram que os Bancos Centrais da Alemanha e do Japão incluem a taxa de câmbio nas suas funções de reação. Lubik e Schorfheide (2007) estimam modelos DSGE e verificam que os bancos centrais da Austrália e Nova Zelândia respondem à taxa de câmbio. Mohanty e Klau (2004), Aizenman, Hutchison E Noy (2011) e Ostry, Ghosh e Chamon ( 2012) encontram que os bancos centrais de vários mercados emergentes respondem à taxa de câmbio. Com relação à resposta assimétrica da política monetária, Ravn (2012) e Hoffmann (2013) encontram evidências de que o Fed responde a quedas nos preços das ações, mas não reage a elevações nesses preços. Hoffmann (2013) verifica ainda que o BCE não responde aos preços das ações, mas reage de forma simétrica às mudanças na taxa de câmbio.

O presente trabalho contribui ao recente debate na medida em que busca verificar se o Banco Central do Brasil (BCB) considera as oscilações nos preços dos ativos (ações e taxa de câmbio) em sua função de reação. Adicionalmente, procura-se analisar se as respostas da política monetária aos preços dos ativos são assimétricas. Para isso, diferentes especificações da função de reação forward-looking do BCB são propostas e estimadas pelo Método Generalizado dos Momen- 
tos (MGM) para o período de metas de inflação. Os resultados dessas estimativas são confrontados com as mensagens enviadas pelo $\mathrm{BCB}$ aos agentes econômicos através das Atas das Reuniões do Comitê de Política Monetária (Copom).

A literatura sobre a reação do $\mathrm{BCB}$ aos preços das ações e taxa de câmbio apresenta resultados divergentes. Klein (2007) encontra que a taxa Selic responde às variações na taxa de câmbio nominal, mas não reage aos preços das ações. Borges Filho (2006) verifica que o BCB responde ao mercado acionário, mas a inclusão dos preços das ações torna o coeficiente do hiato do produto não significativo. Mohanty e Klau (2004) e Soares e Barbosa (2006) estimam regras de Taylor modificadas e constatam que o $\mathrm{BCB}$ responde à taxa de câmbio. Em contraposição, Mello e Moccero (2008) e Furlani, Portugal e Laurini (2010) apresentam evidências de que o BCB não altera a taxa Selic em resposta aos movimentos na taxa de câmbio. O presente trabalho contribui para essa literatura na medida em que leva em consideração possíveis respostas assimétricas do $\mathrm{BCB}$ aos preços dos ativos (ações, taxa de câmbio nominal e taxa de câmbio real), verifica a robustez dos resultados a diferentes formas de estimar os hiatos do produto e dos preços das ações e discute se os resultados estão em conformidade com a descrição do BCB sobre a forma de condução da política monetária após o regime de metas para a inflação.

Os principais resultados deste trabalho podem ser sumarizados da seguinte forma. Primeiro, o BCB tem respondido de forma simétrica aos desvios positivos e negativos da taxa de câmbio em relação a sua tendência. Segundo, as respostas de curto prazo da taxa Selic ao hiato da taxa de câmbio são significativas, mas inferiores às respostas à inflação esperada e hiato do produto. Terceiro, não foram encontradas evidências empíricas de que o $\mathrm{BCB}$ inclui o hiato do preço de ações em sua função de reação. Por fim, as estimativas dos parâmetros implícitos da função de reação mostram que, em geral, apenas a resposta de longo prazo da taxa Selic ao hiato da inflação esperada é significativa. Esse resultado está em conformidade com as visões de Bernanke e Gertler $(1999,2001)$ e Mishkin $(2007,2008)$ de que a autoridade monetária deve responder apenas indiretamente aos preços dos ativos, na medida em que esses preços sinalizem alterações na inflação esperada. Além disso, a ausência de reação de longo prazo ao hiato do produto não implica que o BCB não se importe com a estabilização do produto. Como mostrado por Batini e Haldane (1999), a suavização da taxa de juros e a escolha do horizonte para as metas de inflação já incorporam certo grau de estabilização do produto.

Este trabalho está estruturado em quatro seções, além desta introdução. Na seção 2, faz-se uma breve descrição da estabilização econômica pós-Plano Real e a condução da política monetária sob o regime de metas de inflação. A seção 3 traz as especificações da função de reação que serão estimadas para verificar as respostas do BCB à inflação, ao produto e aos preços dos ativos. A seção 4 apre- 
senta a análise e discussão dos resultados. Por fim, na seção 5 são apresentadas as considerações finais da pesquisa.

\section{Estabilização Econômica pós-1994 e a Política Monetária sob o Regime de Metas de Inflação: uma Breve Visão}

Na década de 1980 e na primeira metade da década de 1990, a economia brasileira enfrentou níveis bastante elevados de inflação. Em junho de 1994, a taxa de inflação foi de 47,43\%, acumulando alta de 4.922,6\% nos últimos doze meses. ${ }^{2}$ Além da inflação elevada, aquele período foi caracterizado pela instabilidade macroeconômica, baixa credibilidade das políticas econômicas adotadas e desequilíbrios no balanço de pagamentos.

Em julho de 1994, o Plano Real foi instituído com a principal finalidade de resolver o problema das altas taxas de inflação. Para isso, adotou-se uma estratégia de metas cambiais em que o preço de venda do real foi fixado em 1 dólar, enquanto o valor de compra era determinado pelas forças de mercado. ${ }^{3}$ Essa medida somou-se à adoção de uma política monetária contracionista caracterizada por elevações nas taxas de juros, exigência de um depósito compulsório de 100\% sobre novas captações e limite sobre a base monetária. Essas políticas contiveram as pressões do lado da demanda e permitiram o controle da inflação. Entre 1994 e 1995, a taxa de inflação anual caiu de $916,5 \%$ para $22,4 \%$.

O processo de estabilização macroeconômica obteve sucesso ao trazer a inflação anual para valores de um dígito já no período 1996-1998. Tal processo abarcou várias reformas econômicas, a saber: i) diminuição do número de companhias estatais devido ao processo de privatizações em alguns setores básicos (tais como telecomunicações, química, bancos e mineração); ii) aprofundamento da liberalização comercial através de uma redução de barreiras (tarifárias e não tarifárias) às importações; e iii) reestruturação do sistema financeiro. Nesse mesmo período, a principal fonte de inércia inflacionária, que era a indexação automática de preços, salários e de alguns contratos, foi reduzida. Do lado real da economia, a taxa média de crescimento do PIB no período de 1994 a 1998 atingiu 3\% ao ano, bem acima da média de 0,2\% observada no período 1990-1993.

Apesar do sucesso em reduzir a inflação, o conjunto de políticas econômicas adotadas pelo governo e BCB não foi capaz de blindar a economia brasileira contra os choques externos. Em 1998, com a moratória da Rússia, houve um aumento do prêmio de risco e uma forte redução no nível das reservas internacionais. Diante disso, o BCB aumentou a taxa de juros Selic para minorar a saída de capitais e

2 Taxa de inflação medida pelo Índice Nacional de Preços ao Consumidor Amplo (IPCA).

3 Entre julho de 1995 e dezembro de 1998, a taxa de câmbio foi conduzida com base em uma meta de desvalorização de 7,5\% ao ano. 
manter o regime cambial. Apesar dessa medida, em janeiro de 1999 o BCB percebeu a sua incapacidade em manter a política cambial vigente e adotou um regime de taxa de câmbio flutuante.

A adoção de um sistema de taxa de câmbio flexível exigiu da autoridade monetária brasileira a implantação de um novo regime de política para ancorar a inflação corrente e as expectativas inflacionárias. O regime de metas de inflação foi formalmente implementado em julho de 1999. O BCB informou ao público a escolha do IPCA como o índice de preços de referência para o novo regime, bem como as metas de inflação para o triênio 1999-2001. As metas foram delimitadas em $8 \%$ para $1999,6 \%$ para 2000 e $4 \%$ para 2001 , com um intervalo de tolerância de $\pm 2 \%$ para cada ano.

A Figura 1 mostra a inflação observada, as metas de inflação (centro da meta e os limites inferior e superior) anunciadas pelo Conselho Monetário Nacional $(\mathrm{CMN})$ e a taxa de juros Selic acumulada no ano para o período 1999-2013. Em geral, observa-se que o BCB obteve êxito em manter a inflação dentro do intervalo de tolerância para a meta central. Nesse período, a média anual para a taxa de inflação foi de 6,6\%, um valor 3,1 pontos percentuais abaixo da média da inflação no período 1995-1998. Entretanto, a inflação ficou abaixo da meta de inflação em apenas quatro dos quinze anos considerados. Em relação à taxa Selic, nota-se uma clara tendência decrescente para esse instrumento de política. Além disso, os períodos em que a inflação aumentou (reduziu) em relação à meta foram, em geral, acompanhados de elevações (quedas) na taxa Selic.

Figura 1 - Inflação observada, taxa de juros Selic e metas para a inflação

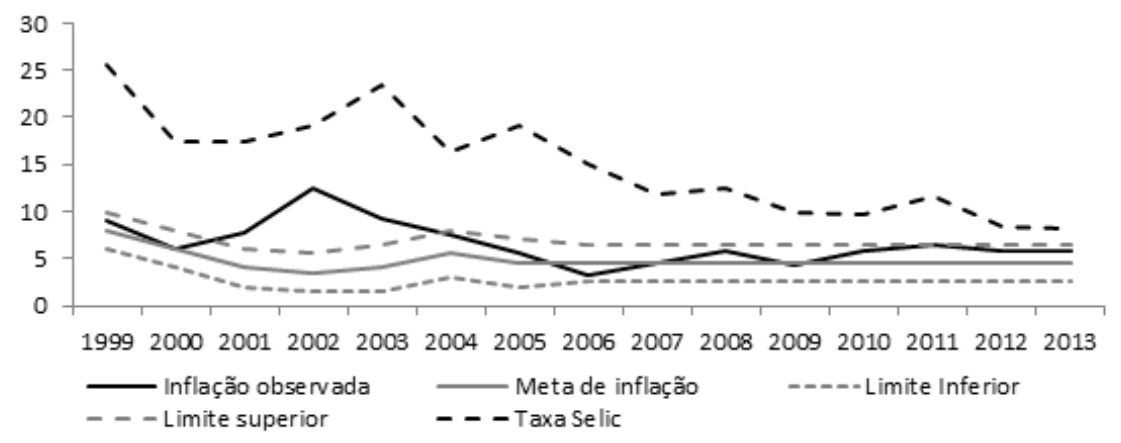

Fonte: Elaboração própria a partir de dados do Banco Central do Brasil.

Nos anos de 2001 e 2002, a combinação de choques externos (crise argentina, ataque terrorista de 11 de setembro e desaceleração da economia mundial) e choques domésticos (crise energética e a crise de confiança acerca da política econômica do novo governo) tiveram um significativo impacto sobre a taxa de câmbio e, consequentemente, sobre a inflação. Em 2001, a inflação ultrapassou o 
intervalo superior da meta em 1,7 ponto percentual, enquanto em 2002 a inflação esteve 7 pontos percentuais acima do limite superior de 5,5\%. No ano de 2003, a forte inércia inflacionária, as elevadas expectativas de inflação e o aumento dos preços administrados foram determinantes para que a inflação ficasse acima do limite superior da meta central, bem como da meta ajustada pelo BCB de $8,5 \%$.

Diante de choques domésticos e externos, o principal objetivo da política monetária no período2001-2003 foi minimizar os efeitos da crise cambial e do aumento dos preços verificados em diversas modalidades de contratos. Em outras palavras, esperava-se que a política monetária limitasse a propagação dos choques para outros preços da economia. Nesse período, a taxa Selic apresentou uma inflexão na sua tendência e voltou a aumentar significativamente, atingindo 23,4\% no ano de 2003.

A partir de 2004, verificou-se a consolidação do regime de metas de inflação como base para orientação da política monetária. A meta de inflação permaneceu constante em 4,5\% e a inflação foi mantida dentro do intervalo de tolerância. Além disso, o país tornou-se menos vulnerável a choques externos e o BCB conseguiu construir credibilidade nas decisões acerca da taxa de juros Selic (SOUZA-SOBRINHO, 2010; MINELLA; SOUZA-SOBRINHO, 2013). Entretanto, é válido ressaltar que, desde 2011, a persistente manutenção da inflação próxima ao limite superior da meta em conjunto com a tendência de redução da taxa Selic parece refletir uma preferência do $\mathrm{BCB}$ e do governo por políticas de expansão da demanda agregada em detrimento do alcance do centro da meta de inflação.

\section{A Função de Reação do Banco Central}

Para analisar a condução da política monetária do $\mathrm{BCB}$ e a sua resposta ao preço de ativos, são estimadas funções de reação análogas à especificação proposta por Clarida, Galí e Gertler (1998). Esses autores apresentaram uma regra de taxa de juros forward-looking que utiliza variáveis futuras para a tomada de decisões de política monetária. O argumento para o uso de variáveis futuras é que certo tempo é necessário para que a inflação e o produto respondam às alterações na taxa de juros. Por essa razão, os bancos centrais deveriam antecipar determinados acontecimentos utilizando regras forward-looking em detrimento de observações passadas. Assim, baseado em Clarida, Galí e Gertler (1998), supõe-se que a autoridade monetária brasileira adota a seguinte regra de taxa de juros:

$$
\mathrm{i}_{\mathrm{t}}^{*}=\bar{l}+\beta\left(\mathrm{E}\left[\pi_{\mathrm{t}, \mathrm{t}+11} \mid \Omega_{\mathrm{t}}\right]-\pi_{\mathrm{t}, \mathrm{t}+11}^{*}\right)+\gamma \mathrm{E}\left[\left(\mathrm{y}_{\mathrm{t}}-\mathrm{y}_{\mathrm{t}}^{*}\right) \mid \Omega_{\mathrm{t}}\right]
$$

A equação (1) mostra as variáveis que o BCB leva em consideração ajustar a meta para a taxa de juros nominal, $\mathrm{i}_{\mathrm{t}}$, no mês t. Tal decisão depende do hiato 
entre a inflação esperada para os próximos doze meses (entre o período t e t+11) e a meta de inflação para os próximos 12 meses, $\pi_{t, t+11}^{*}$, assim como o hiato esperado entre o produto real $\left(\mathrm{y}_{\mathrm{t}}\right)$ e o produto potencial $\left(\mathrm{y}_{\mathrm{t}}^{*}\right)$. Como a inflação futura e produto não são observados no tempo t, torna-se necessária a inclusão dos valores esperados que dependem das informações disponíveis. O termo $\Omega_{t}$ refere-se à informação disponível ao BCB no período t.

Os coeficientes $\beta$ e $\gamma$ na equação (1) ponderam a relevância do hiato da inflação e do produto no ajuste da taxa de juros nominal (TAYLOR, 1993). É válido destacar que se $\beta>1$, o BCB aumenta a meta para a taxa de juros nominal de forma a elevar a meta da taxa de juros real, a fim de estabilizar a inflação. Por outro lado, se $\beta<1$ a autoridade monetária brasileira apenas acomoda o aumento da inflação. Finalmente, a política monetária depende da taxa de juros na qual a inflação e o produto estão em seus níveis de equilíbrio, ou seja, os valores dos hiatos são iguais a zero. Essa taxa é definida como a taxa de juros natural, $\bar{l}$.

Clarida, Galí e Gertler (1998) especificam que os bancos centrais tendem a suavizar mudanças na taxa de juros, isto é, eles não modificam em grande magnitude a taxa de juros entre dois períodos conseguintes. ${ }^{4}$ Assim, seguindo Aragón e Portugal (2010) e Minella e Souza-Sobrinho (2013), assume-se que a taxa de juros observada se ajusta parcialmente à sua meta da seguinte maneira:

$$
i_{t}=\left(1-\rho_{1}-\rho_{2}\right) i_{t}^{*}+\rho_{1} i_{t-1}+\rho_{2} i_{t-2}+v_{t}
$$

onde a suavização da taxa de juros é dada por $\rho_{1+} \rho_{2}$, e o termo de erro $v_{t}$ é um ruído branco. ${ }^{5}$

Substituindo $i_{t}^{*}$ da equação (1) na equação (2), considerando a inflação prevista por previsores profissionais e observável pelo $\mathrm{BCB}, \pi_{\mathrm{t}, \mathrm{t}+11}^{\mathrm{e}}$, como proxy das expectativas (não observáveis) para a inflação, e substituindo o valor esperado pelo valor realizado do hiato do produto, pode-se expressar a regra de taxa de juros da seguinte forma:

$$
\begin{aligned}
i_{t}=\left(1-\rho_{1}-\rho_{2}\right)\left[\bar{\imath}+\beta \tilde{\pi}_{t, t+11}^{e}+\gamma\left(y_{t}-y_{t}^{*}\right)\right]+\rho_{1} i_{t-1}+\rho_{2} i_{t-2}+\varepsilon_{t} \\
=c_{0}+c_{1} \tilde{\pi}_{t, t+11}^{e}+c_{2}\left(y_{t}-y_{t}^{*}\right)+\rho_{1} i_{t-1}+\rho_{2} i_{t-2}+\varepsilon_{t}
\end{aligned}
$$

onde $\tilde{\pi}_{t, t+11}^{e}=\pi_{t, t+11}^{e}-\pi_{t, t+11}^{*}$ é o hiato da inflação esperada, $\mathrm{c}_{0}=\left(1-\rho_{1}-\rho_{2}\right) \bar{l}$, $\mathrm{c}_{1}=\left(1-\rho_{1}-\rho_{2}\right) \beta, \mathrm{c}_{2}=\left(1-\rho_{1}-\rho_{2}\right) \gamma$ e $\varepsilon_{\mathrm{t}}=-\left(1-\rho_{1}-\rho_{2}\right) \gamma\left(\mathrm{y}_{\mathrm{t}}-\mathrm{y}_{\mathrm{t}}{ }_{\mathrm{t}}-\mathrm{E}\left[\mathrm{y}-\mathrm{y}_{\mathrm{t}}{ }_{\mathrm{t}} \mid \Omega_{\mathrm{t}}\right]\right)+\mathrm{v}_{\mathrm{t}}$. Os coeficientes $\mathrm{c}_{1}$ e $\mathrm{c}_{2}$ medem as respostas de curto prazo da taxa de juros de política monetária ao hiato da inflação esperada e hiato do produto. Por sua vez, os parâmetros

4 Para uma discussão mais aprofundada sobre a inserção do termo de suavização da taxa de juros na política monetária, ver Clarida, Galí e Gertler (1998) e Sack (2000).

5 A inclusão da taxa de juros em $t-2$ ajuda a eliminar o problema de autocorrelação dos resíduos. 
implícitos da função de reação, $\beta$ e $\gamma$, medem as respostas de longo prazo da taxa de juros aos hiatos da inflação esperada e do produto, respectivamente.

De acordo com Clarida, Galí e Gertler (1998), Dupor e Conley (2004) e Botzen e Marey (2010), o mercado de ativos pode ser explicitamente incluído na função de reação se é assumido que esse mercado afeta o ajuste da taxa de juros não apenas via inflação futura e produto. Tendo isso em vista, expande-se a regra de política monetária incluindo o desvio do preço das ações, , em relação à sua tendência, . Fazendo isso, a regra de política monetária é dada por:

$$
\begin{gathered}
i_{t}=\left(1-\rho_{1}-\rho_{2}\right)\left[\bar{\imath}+\beta \tilde{\pi}_{t, t+11}^{e}+\gamma\left(y_{t}-y_{t}^{*}\right)+\delta_{2}\left(p_{t}-p_{t}^{*}\right)\right]+\rho_{1} i_{t-1}+\rho_{2} i_{t-2}+\varepsilon_{t} \\
=c_{0}+c_{1} \tilde{\pi}_{t, t+11}^{e}+c_{2}\left(y_{t}-y_{t}^{*}\right)+c_{3}\left(p_{t}-p_{t}^{*}\right)+\rho_{1} i_{t-1}+\rho_{2} i_{t-2}+\varepsilon_{t}
\end{gathered}
$$

onde $c_{3}=\left(1-\rho_{1}-\rho_{2}\right) \delta_{2}$. Como destacado por Hoffmann (2013), o operador de esperança matemática não se faz necessário para o hiato do preço das ações, haja vista que seus valores são conhecidos em qualquer período $t$. O coeficiente $c_{3}\left(\delta_{2}\right)$ captura a reação de curto prazo (longo prazo) do instrumento de política monetária ao hiato do preço das ações.

A equação (4) não possibilita captar uma possível resposta assimétrica da taxa de juros às mudanças nos preços das ações. Assim, para verificar se a autoridade monetária responde assimetricamente às oscilações positivas e negativas nos preços das ações, segue-se Danne e Schnabl (2008) e inclui-se uma variável dummy na equação (4) com a finalidade de se fazer distinção entre cenários onde o preço dos ativos está acima ou abaixo de sua tendência. Em específico, a dummy $D_{t}$ assume valor 0 quando o preço das ações está acima de sua tendência $\left(\mathrm{p}_{\mathrm{t}}>\mathrm{p}_{\mathrm{t}}\right.$ ), e 1 em caso contrário. Fazendo essa inserção, a função de reação assume a seguinte forma:

$$
\begin{aligned}
i_{t} & =\left(1-\rho_{1}-\rho_{2}\right)\left[\bar{\imath}+\beta \tilde{\pi}_{t, t+11}^{e}+\gamma\left(y_{t}-y_{t}^{*}\right)+\left(p_{t}-p_{t}^{*}\right)\left(\delta_{2}+\mu D_{t}\right)\right]+\rho_{1} i_{t-1}+\rho_{2} i_{t-2}+\varepsilon_{t} \\
& =c_{0}+c_{1} \tilde{\pi}_{t, t+11}^{e}+c_{2}\left(y_{t}-y_{t}^{*}\right)+c_{3}\left(p_{t}-p_{t}^{*}\right)+c_{4} D_{t}\left(p_{t}-p_{t}^{*}\right)+\rho_{1} i_{t-1}+\rho_{2} i_{t-2}+\varepsilon_{t}
\end{aligned}
$$

onde $c_{4}=\left(1-\rho_{1}-\rho_{2}\right) \mu$. Na equação (5), o coeficiente $\delta_{2}$ representa a resposta de longo prazo da taxa de juros aos desvios positivos do preço das ações em relação à sua tendência. Por conseguinte, é o efeito adicional de um hiato negativo do preço dos ativos. Um $\mu=0$, implica que a política monetária adotada pelo BCB não reage mais acentuadamente com relação aos valores negativos do hiato do preço das ações.

Além das equações (4) e (5), também serão estimadas duas especificações da função de reação com a finalidade de verificar como o $\mathrm{BCB}$ tem respondido à taxa de câmbio, , e se essa resposta tem sido assimétrica com relação a depreciações e apreciações cambiais. Nesse caso, as funções de reação são dadas por: 


$$
i_{t}=c_{0}+c_{1} \tilde{\pi}_{t, t+11}^{e}+c_{2}\left(y_{t}-y_{t}^{*}\right)+c_{3}\left(e_{t}-e_{t}^{*}\right)+\rho_{1} i_{t-1}+\rho_{2} i_{t-2}+\varepsilon_{t}
$$

e

$$
i_{t}=c_{0}+c_{1} \tilde{\pi}_{t, t+11}^{e}+c_{2}\left(y_{t}-y_{t}^{*}\right)+c_{3}\left(e_{t}-e_{t}^{*}\right)+c_{4} D_{t}^{e}\left(e_{t}-e_{t}^{*}\right)+\rho_{1} i_{t-1}+\rho_{2} i_{t-2}+\varepsilon_{t}(7)
$$

onde $\left(e_{t}-e_{t}\right)$ representa o hiato da taxa de câmbio e $D_{t}^{e}$ assume o valor 0 quando $e_{t}>e_{t}^{*}$, e 1 caso contrário.

\section{Resultados}

Nesta seção são apresentados os dados utilizados na pesquisa e os resultados das estimações de diferentes especificações da função de reação do BCB que incluem preços das ações e taxa de câmbio como regressores.

\subsection{Descrição dos Dados}

Os dados utilizados na estimação das funções de reação (3)-(7) possuem periodicidade mensal e foram obtidos dos sites do Instituto de Pesquisa Econômica Aplicada (Ipea) e do BCB. As observações se iniciam em janeiro de 2002 e se encerram em julho de 2014. A escolha desse período inicial deveu-se a disponibilidade dos dados de expectativas de inflação para os próximos 12 meses e da produção industrial considerada como proxy do PIB. ${ }^{6}$

A taxa de juros ( $\mathrm{i}_{\mathrm{t}}$ ) é representada pela taxa básica de juros da economia brasileira, a taxa Selic mensal anualizada. Esta variável tem sido usada como o principal instrumento de política monetária no regime de metas de inflação.

O hiato da inflação esperada $\left(\tilde{\pi}_{t, t+11}^{e}\right)$ é o desvio da inflação esperada e a meta de inflação para os próximos 12 meses. A inflação esperada $\left(\pi_{t, t+11}^{e}\right)$ diz respeito à mediana das previsões de inflação doze meses a frente (inflação acumulada entre $t$ e $t+11$ ) feitas pelo mercado e coletadas pela Gerência-Executiva de Relacionamento com Investidores (Gerin) do BCB. A série de metas de inflação $\left(\pi_{t, t+11}^{*}\right)$ refere-se às metas para a inflação acumulada nos próximos 12 meses (entre e ). Como o CMN estabelece as metas de inflação para os anos calendário, os dados foram interpolados. ${ }^{7}$

6 A série de expectativas de inflação para os próximos 12 meses é disponibilizada pelo BCB a partir de novembro de 2001. Por sua vez, o índice de produção industrial calculado com a nova metodologia está disponível pelo Instituto Brasileiro de Geografia e Estatística (IBGE) a partir de janeiro de 2002.

7 Na construção da série de metas de inflação, foi considerado o fato de que o BCB perseguiu uma meta ajustada de 8,5\% em 2003 e 5,5\% em 2004, bem como uma meta de 5,1\% em 2005. Para detalhes sobre as metas ajustadas e a meta anunciada para 2005, ver Cartas Abertas (de 2003 e 2004), enviadas pelo BCB ao Ministro da Fazenda, e as notas da reunião do Copom de setembro de 2004 . 
O hiato do produto é calculado tomando-se a diferença entre o logaritmo natural (ln) da produção industrial ajustada sazonalmente (utilizado como proxy para o produto agregado, ) e a sua tendência considerada como proxy do produto potencial, $\mathrm{y}_{\mathrm{t}}{ }^{*}{ }^{8,9} \mathrm{~A}$ tendência do produto foi estimada pelo filtro Hodrick-Prescott (HP). Seguindo Ravn e Uhlig (2002), o parâmetro de suavização utilizado no filtro HP foi igual a 129.600.

De forma análoga ao produto, o hiato do preço das ações é obtido pela diferença entre o ln do IBOVESPA, considerado como proxy do preço das ações $\left(\mathrm{p}_{\mathrm{t}}\right)$, e a sua tendência ( $p_{t}$ ) obtida pelo filtro HP. Por fim, são utilizadas duas séries de taxas de câmbio: o índice da taxa de câmbio efetiva real-IPCA e a taxa de câmbio nominal R \$/US\$ (compra - média do período). O hiato da taxa de câmbio $\left(e_{t}-e_{t}\right.$ ") é calculado pela diferença entre o ln da taxa de câmbio e a sua tendência estimada pelo filtro HP. ${ }^{10}$

\subsection{Estimação da Função de Reação do BCB com Preço das Ações}

Para a estimação da função de reação do $\mathrm{BCB}$, segue-se a literatura que emprega o Método Generalizado dos Momentos (MGM).Essa estratégia empírica é utilizada porque: i)nas regras de política monetária descritas na seção 3, a variável hiato do produto é endógena, isto é, correlacionada com o termo de erro, $\varepsilon_{\mathrm{t}}$;i) há possíveis erros de mensuração com relação às variáveis explicativas em razão da utilização da inflação prevista pelos agentes de mercado $\left(\pi_{t, t+11}^{e}\right)$ como proxy das expectativas (racionais) de inflação $\left(E\left[\pi_{\mathrm{t}, \mathrm{t}+11} \mid \Omega_{\mathrm{t}}\right]\right)$, bem como do uso de proxy para o produto potencial (não observável) da economia brasileira. Faz-se necessário ressaltar que, na presença de variáveis endógenas, o estimador de Mínimos Quadrados Ordinários (MQO) é inconsistente (GREENE, 2003).

Na Tabela 1 são reportadas as estimativas MGM dos parâmetros das especificações (3)-(5) da função de reação do BCB. ${ }^{11}$ Os erros padrão para os coeficientes de longo prazo $\left(\beta, \gamma, \delta_{1,2}, \mu\right)$ foram obtidos pelo método Delta. Os instrumentos usados foram as defasagens (-1) e (-2) da taxa Selic e do hiato da inflação esperada, e as defasagens (-2) e (-3) do hiato do produto. Além disso, as defasagens (-1) e (-2)

8 Para expressar os desvios em termos percentuais, os valores do hiato do produto, hiato do preço dos ativos e hiato da taxa de câmbio foram multiplicados por 100 .

9 A utilização do produto industrial como proxy do PIB tem sido frequente na literatura nacional (ver, por exemplo, Minella et al. (2003), Moura e Carvalho (2010), Aragón e Portugal (2010), Sánchez-Fung (2011) e Aragón e Medeiros (2015).

10 Os testes de raiz unitária $\mathrm{ADF}, \mathrm{KPSS}$ e $\mathrm{MZ}_{\alpha}$ foram realizados para todas as variáveis e podem ser disponibilizados pelos autores. Os resultados mostraram, em geral, que as séries são estacionárias. Entretanto, como destacado por Hsiao (1997a, b), a inferência com estimadores de Variáveis Instrumentais permanece válida mesmo na presença de variáveis não estacionárias e não cointegradas.

11 As estimativas foram obtidas com a matriz de covariância de Newey e West estimada considerando o kernel de Bartlett e bandwidth fixado em 5. 
do hiato do preço dos ativos foram incluídas como instrumentos na estimação das equações (4) e (5), e a defasagem (-1) da interação entre o hiato do preço de ativos e a dummy $D_{t}$ foi incluída como instrumento na função de reação (5). A razão para a inclusão desse conjunto de instrumentos é que as variáveis consideradas pertencem ao conjunto de informação do BCB no período em que ele decide a taxa de juros de política monetária, além de serem potencialmente correlacionadas com os regressores endógenos e ortogonais ao termo de erro da função de reação. Visto que os instrumentos implicam restrições de sobre identificação do modelo, testou-se a validade dessas restrições através do teste $J$ de Hansen (1982). Além disso, o teste $F$ de Cragg-Donald, proposto por Stock e Yogo (2005), é utilizado para testar a hipótese nula de que os instrumentos são fracos. ${ }^{12,13}$ Os resultados desses testes, apresentados na Tabela 1, rejeitam a hipótese de que os instrumentos são fracos. Adicionalmente, o teste $J$ mostra que não se pode rejeitar a hipótese de que as restrições de sobre identificação são satisfeitas.

12 Stock e Yogo (2005) destacam que a presença de instrumentos fracos pode resultar em estimadores MGM viesados. Assim, seguindo esses autores, esse trabalho considerou que os instrumentos são fracos quando o viés do estimador MGM em relação ao viés do estimador MQO é maior do que algum valor $b$ (por exemplo, $b=10 \%)$.

13 Os valores críticos desse teste são apresentados em Stock e Yogo (2005) para uma regressão com até três variáveis explicativas endógenas. Por isso, o teste não foi feito para a função de reação (5). 
Tabela 1 - Especificação da função de reação do BCB usando filtro HP

\begin{tabular}{|c|c|c|c|c|c|c|}
\hline \multirow[b]{2}{*}{ Variável } & \multicolumn{2}{|c|}{ Equação 3} & \multicolumn{2}{|c|}{ Equação 4} & \multicolumn{2}{|c|}{ Equacão 5} \\
\hline & Estimativa & $\begin{array}{c}\text { Erro } \\
\text { padrão }\end{array}$ & Estimativa & $\begin{array}{c}\text { Erro } \\
\text { padrão }\end{array}$ & Estimativa & $\begin{array}{c}\text { Erro } \\
\text { padrão }\end{array}$ \\
\hline $\mathrm{c}_{0}$ & 0,088 & 0,084 & $0,085 * *$ & 0,074 & 0,057 & 0,084 \\
\hline $\mathrm{c}_{1}$ & $0,094^{* * *}$ & 0,022 & $0,093 * *$ & 0,023 & $0,101 * * *$ & 0,023 \\
\hline $\mathrm{c}_{2}$ & $0,034^{* * *}$ & 0,008 & $0,029 * *$ & 0,012 & 0,028 & 0,013 \\
\hline$c_{3}$ & & & 0,0004 & 0,00 & 0,004 & 0,00 \\
\hline $\begin{array}{l}c_{4} \\
\beta\end{array}$ & $7,574^{*}$ & 4,073 & $7,658^{* *}$ & 3,635 & $\begin{array}{c}-0,006 \\
8,017^{*} *\end{array}$ & $\begin{array}{l}0,006 \\
3,665\end{array}$ \\
\hline$\gamma$ & $2,719^{*}$ & 1,548 & 2,388 & 1,677 & 2,214 & 1,568 \\
\hline$\delta_{1,2}$ & & & 0,034 & 0,291 & 0,291 & 0,316 \\
\hline$\mu$ & & & & & $-0,455$ & 0,516 \\
\hline$\rho_{1}$ & $1,645^{* * *}$ & 0,057 & $1,649 * * *$ & 0,068 & $1,639 * * *$ & 0,085 \\
\hline$\rho_{2}$ & $-0,658^{* *}$ & 0,060 & $-0,661 * *$ & 0,070 & $-0,652^{* *}$ & 0,086 \\
\hline J-stat ${ }^{a}$ & 0,923 & & 1,995 & & 2,164 & \\
\hline P-valor & 0,630 & & 0,573 & & 0,548 & \\
\hline $\begin{array}{c}\text { Cragg- } \\
\text { Donald } \\
\text { F- stat }\end{array}$ & $29,61^{\dagger}$ & & $9,23^{\dagger \dagger}$ & & $23,46^{\dagger \dagger}$ & \\
\hline
\end{tabular}

Fonte: Elaboração própria.

Notas: * Significância a 10\%; * Significância a 5\%; * * Significância a 1\%. ' Indica que o viés relativo do estimador MGM em relação ao estimador MQO é no máximo $5 \%$. ${ }^{\dagger \dagger}$ Indica que o viés relativo do estimador MGM em relação ao estimador MQO é no máximo $10 \%$. ${ }^{a} \mathrm{O}$ teste $J$ de Hansen é o teste para restrições sobre identificadas. A hipótese nula é de que todos os instrumentos são válidos.

Com relação às estimativas dos parâmetros, observa-se que a resposta de curto prazo da taxa Selic à inflação esperada, $c_{1}$, é significativa a 1\% em todas as especificações. Adicionalmente, as estimativas do coeficiente de longo prazo da inflação, $\beta$, mostram-se significativas e maiores do que 1. Para a equação (4), por exemplo, o valor do coeficiente $\beta$ indica que uma elevação de 1 ponto percentual no hiato da inflação esperada acarreta um aumento de aproximadamente 7,6 pontos percentuais na taxa de juros Selic. Isso evidencia a característica forwardlooking da política monetária brasileira e aponta para uma atenção especial por parte do BCB com a questão do controle inflacionário no Brasil.

Pode-se destacar que as estimativas para o coeficiente $\beta$ estão acima daquelas observadas para os bancos centrais de economias desenvolvidas, tais como o Fed, Bundesbank, Banco do Japão e o Banco Central Europeu (CLARIDA; GALÍ; GERTLER, 1998; HOFFMANN, 2013). Isso pode ser explicado pelo histórico de 
hiperinflação enfrentado pela economia brasileira em um passado recente, o que pode ter elevado a sensibilidade da autoridade monetária às oscilações nos níveis de inflação considerados toleráveis. Em um regime de metas para a inflação, busca-se, acima de tudo, a convergência da inflação para o centro da meta estipulada, o que pode exigir reações mais intensas da política monetária via mudança na taxa juros para se atingir tal objetivo.

Ao se incluir o hiato do preço das ações na função de reação do BCB, verifica-se que os resultados permanecem similares aos da Eq. (3). No entanto, os coeficientes de curto e longo prazo da resposta da taxa Selic ao hiato do produto perdem significância. Apenas para a função de reação (3), a estimativa da resposta de longo prazo da taxa Selic ao hiato do produto $(\gamma)$ é estatisticamente significativa a 10\%, mas inferior à resposta ao hiato da inflação. Essa prioridade do BCB ao combate à inflação também é verificada em Minella et al. (2003), Moura e Carvalho (2010), Aragón e Portugal (2010), Sánchez-Fung (2011) e Aragón e Medeiros (2015).

Paralelamente, o coeficiente do hiato do preço das ações não se mostra significante. Isso sugere que o preço dos ativos não afetou diretamente as decisões de política monetária no período 2002-2014.Todavia, seguindo Dupor e Conley (2004) e Borges Filho (2006), é possível argumentar que uma elevada colinearidade entre o hiato do produto e o hiato do preço das ações pode estar afetando a significância estatística dessas variáveis e dificultando a identificação da resposta do $\mathrm{BCB}$ a cada uma dessas variáveis. Para verificar isso, foram calculadas a matriz de correlação e os Fatores de Inflação da Variância (FIV) para os regressores endógenos da função de reação (4). Os resultados mostraram que a correlação entre o hiato do produto e o hiato do preço das ações foi igual a 0,58 e os FIV foram menores que 2, o que sugere a ausência de forte multicolinearidade entre essas variáveis. ${ }^{14,15}$ Dessa forma, os resultados da Eq. (4) corroboram a ideia de que a política monetária do $\mathrm{BCB}$ parece ser mais ativa no que diz respeito ao combate à inflação.

A inclusão da dummy de assimetria na Eq. (5) reforça os resultados apontados na Eq. (4). Em geral, os resultados para $\beta, \gamma$ e $\delta$ não se alteram. Por sua vez, a estimativa para o coeficiente $\mu$ não é estatisticamente significante. Isso indica que a política monetária implementada pelo BCB não reage mais acentuadamente com relação aos valores negativos do hiato do preço das ações.

Finalmente, a suavização da taxa Selic, dada por $\rho_{1}+\rho_{2}$, foi aproximadamente 0,99 para as três especificações da função de reação do BCB. Isso está em linha com a literatura sobre suavização da taxa de juros de curto prazo e reflete o ajus-

14 É válido mencionar que não foram encontradas elevadas correlações entre o hiato da inflação esperada e os demais regressores endógenos. Por exemplo, a correlação entre o hiato da inflação esperada e o hiato do produto foi de -0,021, enquanto que a correlação entre o hiato da inflação esperada e o hiato do preço dos ativos foi de -0,37.

15 Resultados análogos foram encontrados para a correlação e FIV dos regressores endógenos da função de reação (5). 
tamento desse instrumento de política monetária em intervalos e em montantes discretos. ${ }^{16}$

\subsubsection{Análise de Robustez}

Embora o filtro HP seja comumente utilizado, vários trabalhos analisam as limitações e problemas dessa metodologia. Por exemplo, Cogley e Nason (1995) destacam o fato de que o filtro pode induzir a ciclos espúrios nas séries de tempo filtradas com a "forma espectral típica" de Granger (1966). King e Rebelo (1993) sustentam que a aplicação mecânica do filtro pode alterar as propriedades inerentes da série, tais como a volatilidade e correlação com outras séries. Esses autores destacam ainda que o filtro HP altera a volatilidade relativa (o desvio padrão da variável dividido pelo desvio padrão do produto) de diferentes séries. Baxter e King (1999) apontam que o filtro HP distorce os valores filtrados nas extremidades das séries.

Diante disso, procurou-se inicialmente verificar a robustez dos resultados encontrados através da estimação das especificações (3)-(5) usando-se o filtro CF, proposto por Christiano e Fitzgerald (2003), para obter o hiato do produto e o hiato do preço das ações. Basicamente, os resultados apresentados na Tabela 2 para os coeficientes de curto prazo corroboram aqueles encontrados através da utilização do filtro HP. Notadamente, a relevância do papel do controle da inflação no regime de metas ganha destaque na política monetária do BCB. É importante notar que as estimativas de $\beta$ são um pouco menores se comparadas aos valores encontrados na Tabela 1. Entretanto, diferente dos resultados da subseção anterior, os valores desse coeficiente não se apresentam estatisticamente significantes em nenhuma especificação da função de reação do BCB.

16 Ver Goodfriend (1991) e Rudebusch (1995) para detalhes sobre a suavização da taxa de juros de curto prazo. Ver também Minella et al. (2003), Moura e Carvalho (2010) e Aragón e Portugal (2010) para outras evidências empíricas da suavização da taxa de juros Selic. 
Tabela 2 - Especificação da função de reação do BCB usando filtro CF

\begin{tabular}{|c|c|c|c|c|c|c|}
\hline \multirow[b]{2}{*}{ Variável } & \multicolumn{2}{|c|}{ Equação 3} & \multicolumn{2}{|c|}{ Equação 4} & \multicolumn{2}{|c|}{ Equação 5} \\
\hline & Estimativa & $\begin{array}{c}\text { Erro } \\
\text { padrão }\end{array}$ & Estimativa & $\begin{array}{c}\text { Erro } \\
\text { padrão }\end{array}$ & Estimativa & $\begin{array}{c}\text { Erro } \\
\text { padrão }\end{array}$ \\
\hline $\mathrm{c}_{0}$ & 0,109 & 0,095 & 0,054 & 0,086 & 0,004 & 0,082 \\
\hline $\mathrm{C}_{1}$ & $0,077 * * *$ & 0,027 & $0,062 * *$ & 0,026 & $0,076 * * *$ & 0,026 \\
\hline $\mathrm{c}_{2}$ & $0,027 * * *$ & 0,006 & $0,053 * * *$ & 0,018 & $0,057 * * *$ & 0,017 \\
\hline $\mathrm{c}_{3}$ & & & $-0,007$ & 0,004 & $-0,002$ & 0,005 \\
\hline $\begin{array}{l}\mathrm{c}_{4} \\
\beta\end{array}$ & 5,757 & 3,722 & 6,288 & 5,019 & $\begin{array}{l}-0,007 \\
7,934\end{array}$ & $\begin{array}{l}0,006 \\
5,647\end{array}$ \\
\hline$\gamma$ & 2,014 & 1,317 & 5,440 & 3,800 & 5,942 & 4,040 \\
\hline$\delta_{1,2}$ & & & $-0,671$ & 0,497 & $-0,215$ & 0,545 \\
\hline$\mu$ & & & & & $-0,775$ & 0,728 \\
\hline$\rho_{1}$ & $1,682 * * *$ & 0,060 & $1,598 * * *$ & 0,067 & $1,568 * * *$ & 0,071 \\
\hline$\rho_{2}$ & $-0,696 * * *$ & 0,063 & $-0,608 * * *$ & 0,068 & $-0,577 * * *$ & 0,071 \\
\hline J-stat ${ }^{a}$ & 2,539 & & 5,357 & & 5,184 & \\
\hline P-valor & 0,281 & & 0,147 & & 0,159 & \\
\hline $\begin{array}{c}\text { Cragg- } \\
\text { Donald F- stat }\end{array}$ & $81,77^{\dagger}$ & & $51,29^{\dagger}$ & & $43,39^{\dagger}$ & \\
\hline
\end{tabular}

Fonte: Elaboração própria.

Notas: * Significância a 10\%; * Significância a 5\%; * * Significância a 1\%. † Indica que o viés relativo do estimador MGM em relação ao estimador MQO é no máximo 5\%. ${ }^{\text {a }} \mathrm{O}$ teste $J$ de Hansen é para restrições sobre identificadas. A hipótese nula é de que todos os instrumentos são válidos.

O coeficiente de longo-prazo do hiato do produto, $\gamma$, perde significância na Eq. (3) e apresenta resultados similares nas equações. (4) e (5). Os resultados para essa variável coadunam com aqueles encontrados na Tabela 1 ao mostrar o pouco destaque dado ao hiato do produto na função de reação do BCB. Por sua vez, após se incluir o hiato dos ativos, os resultados não diferem daqueles encontrados anteriormente. Em suma, os resultados obtidos com a utilização do filtro $\mathrm{CF}$ indicam que o BCB não leva em consideração as mudanças do mercado de ativos nas decisões acerca da taxa Selic. 
Tabela 3 - Especificação da função de reação do BCB usando um modelo de tendência linear para estimação das tendências do produto e do preço das ações.

\begin{tabular}{c|cc|cc|cc}
\hline \multirow{2}{*}{ Variável } & \multicolumn{2}{|c|}{ Equacão 3 } & \multicolumn{2}{c|}{ Equacão 4 } & \multicolumn{2}{c}{ Equacão 5 } \\
& Estimativa & $\begin{array}{c}\text { Erro } \\
\text { padrão }\end{array}$ & Estimativa & $\begin{array}{c}\text { Erro } \\
\text { padrão }\end{array}$ & Estimativa & $\begin{array}{c}\text { Erro } \\
\text { padrão }\end{array}$ \\
\hline $\mathrm{C}_{0}$ & 0,064 & 0,067 & 0,071 & 0,064 & 0,042 & 0,089 \\
$\mathrm{C}_{1}$ & $0,138^{* * *}$ & 0,024 & $0,120^{* * *}$ & 0,031 & $0,121^{* * *}$ & 0,030 \\
$\mathrm{C}_{2}$ & $0,025^{* * *}$ & 0,006 & $0,034^{* *}$ & 0,013 & $0,033^{* * *}$ & 0,013 \\
$\mathrm{C}_{3}$ & & & $-0,002$ & 0,002 & $-0,001$ & 0,003 \\
$\mathrm{C}_{4}$ & & & & & $-0,002$ & 0,003 \\
$\beta$ & $10,878^{* *}$ & 4,476 & $9,823^{* *}$ & 3,871 & $10,357^{* *}$ & 4,383 \\
$\gamma$ & $1,976^{* *}$ & 0,813 & $2,793^{*}$ & 1,682 & 2,817 & 1,734 \\
$\delta_{1,2}$ & & & $-0,155$ & 0,210 & $-0,086$ & 0,230 \\
$\mu$ & & & & & $-0,128$ & 0,281 \\
$\rho_{1}$ & $1,619^{* * *}$ & 0,052 & $1,596^{* * *}$ & 0,057 & $1,586 * * *$ & 0,062 \\
$\rho_{2}$ & $-0,632^{* * *}$ & 0,053 & $-0,609 * * *$ & 0,058 & $-0,598^{* * *}$ & 0,063 \\
\hline J-stat & 0,038 & & 1,757 & & 1,623 & \\
P-valor & 0,981 & & 0,624 & & 0,654 & \\
\hline Cragg- & $33,31^{\dagger}$ & & $8,30^{* \dagger}$ & & & \\
\hline Donald F- stat & & & & & & \\
\hline
\end{tabular}

Fonte: Elaboração própria.

Notas: * Significância a 10\%; * "Significância a 5\%; * * Significância a 1\%. †'Indica que o viés relativo do estimador MGM em relação ao estimador MQO é no máximo 5\%. " Indica que o viés relativo do estimador MGM em relação ao estimador MQO é no máximo 10\%. ${ }^{a} \mathrm{O}$ teste $J$ de Hansen é o teste para restrições sobre identificadas. A hipótese nula é de que todos os instrumentos são válidos.

O segundo exercício de robustez foi estimar a função de reação considerando o hiato do produto e hiato do preço dos ativos obtidos através do modelo de tendência linear na estimação de $y_{t}^{*} e p_{t}^{*}$. Os resultados foram apresentados na Tabela 3. Como se pôde observar, as estimativas dos coeficientes mostram que, em geral, o BCB altera a taxa Selic em resposta ao hiato da inflação esperada e hiato do produto, mas não reage ao hiato do preço das ações.

\subsection{Resposta do BCB à Taxa de Câmbio}

Nesta subseção, são apresentados os resultados referentes à especificação da função de reação proposta para verificar a resposta do BCB à taxa de câmbio. ${ }^{17}$

17 Nesta subseção, preferiu-se estimar a função de reação excluindo o hiato do preço das ações por 
Duas variáveis de taxa de câmbio foram consideradas: a taxa nominal de câmbio (R\$/US\$) e a taxa de câmbio real efetiva. Em ambas as especificações, o filtro HP foi utilizado para obter o hiato do produto e da taxa de câmbio. Os resultados são apresentados na Tabela 4.

Inicialmente, pode-se verificar que as respostas de curto prazo da taxa Selic ao hiato da inflação esperada, ao hiato do produto e ao hiato da taxa de câmbio são significantes a $10 \%$ em todas as especificações.

Tabela 4 - Especificação da função de reação do BCB com taxa de câmbio

\begin{tabular}{|c|c|c|c|c|c|c|c|c|}
\hline \multirow{3}{*}{$\begin{array}{c}\text { Variá- } \\
\text { vel }\end{array}$} & \multicolumn{4}{|c|}{ Taxa de câmbio nominal } & \multicolumn{4}{|c|}{ Taxa de câmbio real efetiva } \\
\hline & \multicolumn{2}{|c|}{ Equação 6} & \multicolumn{2}{|c|}{ Equação 7} & \multicolumn{2}{|c|}{ Equação 6} & \multicolumn{2}{|c|}{ Equação 7} \\
\hline & $\begin{array}{c}\text { Estima- } \\
\text { tiva }\end{array}$ & $\begin{array}{c}\text { Erro } \\
\text { padrão }\end{array}$ & $\begin{array}{c}\text { Estima- } \\
\text { tiva }\end{array}$ & \begin{tabular}{|c|} 
Erro \\
padrão
\end{tabular} & $\begin{array}{c}\text { Estima- } \\
\text { tiva }\end{array}$ & \begin{tabular}{|c|} 
Erro \\
padrão
\end{tabular} & $\begin{array}{c}\text { Estima- } \\
\text { tiva }\end{array}$ & $\begin{array}{c}\text { Erro } \\
\text { padrão }\end{array}$ \\
\hline $\mathrm{c}_{0}$ & 0,041 & 0,074 & 0,032 & 0,080 & 0,037 & 0,077 & 0,044 & 0,076 \\
\hline $\mathrm{c}_{1}$ & $0,086^{* * *}$ & 0,026 & $0,078 * * *$ & 0,025 & $0,090 * * *$ & 0,024 & $0,080 * * *$ & 0,024 \\
\hline $\mathrm{c}_{2}$ & $0,051^{* * *}$ & 0,014 & $0,049^{* * *}$ & 0,015 & $0,044^{* * *}$ & 0,011 & $0,041^{* * *}$ & 0,010 \\
\hline $\mathrm{C}_{3}$ & $0,009^{*}$ & 0,005 & $0,013^{*}$ & 0,008 & $0,008^{* *}$ & 0,004 & $0,011^{*}$ & 0,006 \\
\hline $\mathrm{C}_{4}$ & & & -0.008 & 0.008 & & & $-0,005$ & 0,009 \\
\hline$\beta$ & 10,09 & 6,601 & $8,263^{*}$ & 4,984 & 10,85 & 7,453 & $8,360^{*}$ & 5,046 \\
\hline$\gamma$ & 5,957 & 4,490 & 5,139 & 3,788 & 5,274 & 4,238 & 4,285 & 3,090 \\
\hline$\delta_{1,2}$ & 1,030 & 0,937 & 1,389 & 1,224 & 1,012 & 0,966 & 1,184 & 1,025 \\
\hline$\mu$ & & & $-0,834$ & 0,961 & & & $-0,569$ & 0,946 \\
\hline$\rho_{1}$ & $1,584 * * *$ & 0,065 & $1,587 * *$ & 0,072 & $1,591^{* * *}$ & 0,063 & $1,604^{* * *}$ & 0,063 \\
\hline$\rho_{2}$ & $-0,593^{* * *}$ & 0,067 & $-0,597^{* *}$ & 0,074 & $-0,600 * * *$ & 0,065 & $-0,614^{* * *}$ & 0,065 \\
\hline J-stat ${ }^{a}$ & 2,501 & & 3,015 & & 2,776 & & 3,031 & \\
\hline P-valor & 0,475 & & 0,389 & & 0,428 & & 0,386 & \\
\hline $\begin{array}{c}\text { Cragg- } \\
\text { Donald } \\
\text { F-stat }\end{array}$ & $9,319^{\dagger+}$ & & $9.162^{\dagger \dagger}$ & & $13,62^{\dagger}$ & & $4.173^{\dagger}$ & \\
\hline
\end{tabular}

Fonte: Elaboração própria.

Notas: * Significância a 10\%; * Significância a 5\%; ** Significância a 1\%. "† Indica que o viés relativo do estimador MGM em relação ao estimador MQO é no máximo $10 \%$. ${ }^{\text {a }}$ O teste $J$ de Hansen é o teste para restrições sobre identificadas. A hipótese nula é de que todos os instrumentos são válidos.

duas razões: i) os resultados da seção 4.2 mostraram que o preço das ações não exerceu efeito significativo sobre a taxa Selic; ii) para evitar possíveis problemas de identificação que poderiam surgir em razão da multicolinearidade entre regressores. Entretanto, é importante ressaltar que os resultados desta subseção são, em geral, robustos à inclusão do preço dos ativos na regressão. Os resultados podem ser disponibilizados depois de requisitados aos autores. 
As estimativas do coeficiente c_4 não são estatisticamente diferentes de zero, indicando que, no curto prazo, o $\mathrm{BCB}$ não responde de forma assimétrica às variações positivas e negativas do hiato da taxa de câmbio. Com relação aos coeficientes de longo prazo, foi possível observar que apenas a resposta da taxa Selic ao hiato da inflação esperada na função de reação (7) foi significativa a 10\%.

\subsection{Discussão}

Os preços dos ativos podem afetar a economia real e a taxa de inflação de várias maneiras. Por exemplo, uma elevação nos preços das ações pode aumentar os gastos com consumo através dos seus efeitos sobre a riqueza das famílias. As mudanças nos preços dos ativos também afetam os balanços das famílias, firmas e intermediários financeiros. Firmas e famílias podem usar seus ativos como colaterais. Um aumento nos preços dos ativos eleva os valores dos colaterais disponíveis e aumenta o acesso ao crédito. Por sua vez, os intermediários financeiros podem elevar a oferta de crédito e reduzir a taxa de juros sobre empréstimos. Assim, um aumento nos preços dos ativos pode elevar o fluxo de crédito e afetar positivamente os gastos com consumo e investimento, a demanda agregada e, consequentemente, a taxa de inflação. Com relação à taxa de câmbio, uma depreciação cambial pode aumentar a inflação através: i) do aumento dos preços dos bens importados; ii) da elevação das exportações e, consequentemente, da demanda agregada. Entretanto, em uma economia na qual famílias e firmas apresentam uma parte de suas dívidas em moeda estrangeira, o aumento da taxa de câmbio pode afetar negativamente os balanços dos agentes econômicos, o fluxo de crédito, o emprego e o produto agregado.

O BCB tem destacado a importância dos preços dos ativos em várias ocasiões. Em março de 2001, o BCB revelou a sua preocupação com os efeitos da taxa de câmbio, afirmando que "[...] a magnitude da variação cambial recente [...] pode aumentar o grau de repasse para os preços domésticos. Neste caso, a pressão inflacionária originada no canal de câmbio poderia elevar a taxa de inflação deste ano" (BANCO CENTRAL DO BRASIL, 2001a). Na reunião de junho daquele ano, o Copom justificou as elevações na taxa Selic, observadas entre os meses de março e maio, dizendo que "o potencial de repasse da depreciação cambial para os preços foi um dos motivos que justificou a reação da política monetária no período, elevando a taxa de juros para procurar neutralizar estes efeitos" (BANCO CENTRAL DO BRASIL, 2001c). Nessa mesma reunião, o BCB “[...] concluiu que a persistência das pressões já existentes sobre a taxa de inflação e o potencial efeito de um processo instável da depreciação da taxa de câmbio sobre os preços recomendam [...] uma elevação significativa da taxa de juros [...]" (BANCO CENTRAL DO BRASIL, 2001c). 
Em 2002, com a crise de confiança e a forte depreciação cambial, o BCB afirmou que:

O aumento da projeção de inflação para acima da meta ajustada para 2003 recomenda uma política monetária mais restritiva, mesmo que a causa primária da inflação não esteja relacionada com um aumento da demanda, mas sim com o efeito sobre os preços domésticos de uma depreciação cambial significativa. Uma política monetária mais restritiva diminui o repasse da desvalorização cambial para os preços e melhora as expectativas de inflação. (BANCO CENTRAL DO BRASIL, 2002).

Naquela ocasião, os membros do Copom decidiram, por unanimidade, elevar a meta para a taxa Selic de $18 \%$ a.a. para $21 \%$ a.a. Essa tem sido a maior variação deste instrumento de política na história do regime de metas de inflação do Brasil.

Em 2013, o Copom voltou a destacar a importância dos preços dos ativos na condução da política monetária. Na sua $172^{\text {a }}$ reunião, o Copom afirmou que "[...] os desenvolvimentos no âmbito parafiscal e no mercado de ativos são partes importantes do contexto no qual decisões futuras de política monetária serão tomadas, [...]" (BANCO CENTRAL DO BRASIL, 2013a).Na 176ªreunião, o BCB ressaltou que "[...] a citada depreciação cambial constitui fonte de pressão inflacionária em prazos mais curtos. No entanto, os efeitos secundários dela decorrentes, [...], podem e devem ser limitados pela adequada condução da política monetária" (BANCO CENTRAL DO BRASIL, 2013b).

Embora as citações acima indiquem que os preços dos ativos são relevantes para a condução da política monetária brasileira, as estimações da função de reação mostraram que a taxa Selic responde ao hiato da inflação esperada, mas não reage no longo prazo às mudanças nos preços dos ativos. Esses resultados parecem refletir a visão do Copom sobre como a política monetária deve ser conduzida no regime de metas para a inflação. Por exemplo, na 58 a reunião do Copom, realizada nos dias 17 e 18 de abril de 2001, o BCB descreveu o objetivo da política monetária atual e a diferença com a relação ao regime de metas cambiais, dizendo:

O Copom avaliou que cabe reforçar o entendimento de alguns conceitos básicos que guiam a sua atuação. O controle da inflação de acordo com as metas determinadas pelo Governo é o objetivo principal do Banco Central. Ao contrário do regime anterior, o nível da taxa de câmbio não é a meta do Banco Central. Assim como não o é qualquer outro preço específico da economia. Variações da taxa de câmbio só são relevantes na medida em que haja impacto sobre a taxa de inflação do IPCA._Como a relação entre câmbio e inflação depende de muitos fatores (se a depreciação é permanente ou temporária; se haverá repasse aos preços ou não), é essencial enfatizar que a meta é a inflação e não a taxa de câmbio. (BANCO CENTRAL DO BRASIL, 2001b, grifo nosso). 
Em 2002, a autoridade monetária brasileira reforçou a importância da taxa de câmbio na condução de sua política afirmando que:

Os membros do Copom enfatizaram que, apesar da importância da recente depreciação cambial para o aumento das perspectivas de inflação, a política monetária continua sendo calibrada exclusivamente para que a inflação se situe dentro da trajetória de suas metas, não visando determinar um nível para a taxa de câmbio. (BANCO CENTRAL DO BRASIL, 2002, grifo nosso).

$\mathrm{Na} 143^{\mathrm{a}}$ reunião do Copom, o $\mathrm{BCB}$ voltou a destacar o papel dos preços dos ativos dizendo que "[...] movimentos específicos de preços de ativos só são relevantes para a política monetária na medida em que tenham algum impacto sobre a trajetória prospectiva para a inflação" (BANCO CENTRAL DO BRASIL, 2009).

A ausência de significância estatística das respostas de longo prazo da taxa Selic aos preços dos ativos pode ser justificada por várias razões. Primeiro, ela pode refletir as dificuldades da autoridade monetária brasileira em identificar alterações nos preços dos ativos que não estão relacionadas aos fundamentos econômicos. Nesse ambiente de incerteza, uma resposta ativa da política monetária a esses preços pode desestabilizar a economia (BERNANKE; GERTLER, 1999). Segundo, a colinearidade entre os regressores incluídos na função de reação pode afetar a precisa identificação e mensuração da resposta do BCB aos preços dos ativos. Terceiro, os efeitos dos preços das ações sobre a riqueza das famílias brasileiras podem ser baixos. Os dados da Pesquisa de Orçamentos Familiares (POF), realizada pelo IBGE, indicaram que as aplicações financeiras responderam apenas a 12,7\% da taxa de poupança das famílias em 2009 (BANCO CENTRAL DO BRASIL, jan. 2013).$^{18}$ Essa baixa taxa de poupança na forma de ativos financeiros pode limitar os efeitos das oscilações nos preços das ações sobre o consumo das famílias, demanda agregada, produto e taxa de inflação. ${ }^{19}$ Finalmente, a redução do repasse cambial para a inflação observada e expectativas de inflação, documentada por BCB (BANCO CENTRAL DO BRASIL, 2011), Carvalho e Minella (2012) e Alves et al. (2013), sugere que os ganhos de reagira taxa de câmbio podem ser pequenos para a autoridade monetária brasileira.

\section{Considerações Finais}

Neste trabalho, foram estimadas diferentes especificações da função de reação do BCB para investigar a influência do mercado de ativos nas decisões de

18 Nesse ano, a taxa de poupança familiar (razão entre poupança familiar e renda disponível familiar) foi de $5,5 \%$.

19 O BCB também sugere que o mecanismo de transmissão da política monetária via mercado de ativos é pouco relevante porque o mercado de ações brasileiro é menos desenvolvido do que o de outras economias (BANCO CENTRAL DO BRASIL, 2007). 
política monetária sob o regime de metas para a inflação. Em adição, buscou-se identificar se essas reações se dariam de modo assimétrico com relação às variações positivas e negativas dos preços dos ativos. A estratégia empírica se baseou na utilização do MGM para lidar com as limitações do método de MQO na presença de regressores endógenos.

As estimativas dos coeficientes para a função de reação baseada no uso do filtro HP e no hiato dos preços das ações indicaram que uma atenção especial é dada pelo BCB à questão do controle inflacionário. Em geral, observou-se que os coeficientes de curto e longo prazo medindo a reação da taxa Selic ao hiato da inflação esperada foram significativos. Esse resultado está em conformidade com aqueles encontrado por Minella et al. (2003), Moura e Carvalho (2010), Aragón e Portugal (2010), Sánchez-Fung (2011) e Aragón e Medeiros (2015).

Com relação ao hiato do produto, verificou-se que a resposta de curto prazo da autoridade monetária brasileira a essa variável foi significante, porém inferior à reação ao hiato da inflação esperada. Em contraposição, os resultados relacionados ao coeficiente de longo prazo do hiato do produto foram, em geral, não significativos. Entretanto, é importante ressaltar que a ausência de uma reação positiva ao hiato do produto não implica dizer que o $\mathrm{BCB}$ ignora a estabilização do produto. Como argumentado por Batini e Haldane (1999), a suavização da taxa de juros e a escolha do horizonte para as metas já incorporam certo grau de estabilização do produto.

O coeficiente relacionado ao hiato do preço das ações não apresentou significância estatística. Desse modo, as oscilações no mercado de ações pareceram não afetar diretamente as decisões de política monetária no período 2002-2014. Adicionalmente, o coeficiente de assimetria não foi significante, o que descarta a hipótese de que a política monetária adotada pelo $\mathrm{BCB}$ reagiu mais acentuadamente aos valores negativos do hiato do preço das ações. Este conjunto de resultados está em conformidade com as declarações dadas pelo BCB nas atas das reuniões do Copom, bem como com os argumentos de Bernanke e Gertler (1999, 2001) e Mishkin $(2007,2008)$ de que o banco central deve reagir apenas indiretamente aos preços dos ativos, na medida em esses preços indiquem mudanças na inflação esperada.

De modo complementar, ao se utilizar a especificação da função de reação com o hiato da taxa de câmbio em detrimento das ações, observa-se que a taxa Selic responde, no curto prazo, às variações cambiais. Entretanto, apenas o coeficiente de longo prazo medindo a reação da política monetária ao hiato da inflação esperada foi significativo em duas de quatro especificações consideradas. Por fim, em nenhuma especificação estimada encontraram-se evidências de que o BCB responde de forma assimétrica ao hiato da taxa de câmbio. 


\section{Referências}

AIZENMAN J.; HUTCHISON, M.; NOY, I. Inflation targeting and real exchange rates in emerging markets. World Development, v. 39, n. 5, p. 712-724, 2011.

AKRAM, F. Q.; GUNNAR, R.; EITRHEIM, O. Monetary policy and asset prices: to respond or not? International Journal of Finance and Economics, v. 11, n. 3, p. 279-292, 2006.

ALVES, P. et al. Preços Administrados: projeção e repasse cambial. Brasília, DF: Banco Central do Brasil, 2013. (Texto para discussão, n. 305).

ARAGÓN, E. K. S. B.; MEDEIROS, G. B. Monetary policy in Brazil: evidence of a reaction function with time-varying parameters and endogenous regressors. Empirical Economics, v. 48, n. 2, p. 557-575, 2015.

ARAGÓN, E. K. S. B.; PORTUGAL, M. S. Nonlinearities in Central Bank of Brazil's reaction function: the case of asymmetric preferences. Estudos Econômicos, v. 40, n. 2, p. 373-399, 2010.

BANCO CENTRAL DO BRASIL. Carta aberta ao Ministro da Fazenda, 2003.

. Carta aberta ao Ministro da Fazenda, 2004.

. Modelos de projeção: atualização e aperfeiçoamentos. Relatório de Inflação, jun. 2011.

Notas da $143^{a}$ reunião do comitê de política monetária do banco central do Brasil (COPOM). In: REUNIÃO DO COMITÊ DE POLÍTICA MONETÁRIA DO BANCO CENTRAL DO BRASIL, 143., 2009, Brasília, DF. Ata... Brasília, DF: Banco Central do Brasil, jun. 2009.

. Notas da $172^{a}$ reunião do comitê de política monetária do banco central do Brasil (COPOM). In: REUNIÃO DO COMITÊ DE POLÍTICA MONETÁRIA DO BANCO CENTRAL DO BRASIL, 172., 2013, Brasília, DF. Ata... Brasília, DF: Banco Central do Brasil, jan. 2013a.

. Notas da $176^{a}$ reunião do comitê de política monetária do banco central do Brasil (COPOM). In: REUNIÃO DO COMITÊ DE POLÍTICA MONETÁRIA DO BANCO CENTRAL DO BRASIL, 176., 2013, Brasília, DF. Ata... Brasília, DF: Banco Central do Brasil, jul. 2013b.

. Notas da $57^{a}$ reunião do comitê de política monetária do banco central do Brasil (COPOM). In: REUNIÃO DO COMITÊ DE POLÍTICA MONETÁRIA DO BANCO CENTRAL DO BRASIL, 57., 2001, Brasília, DF. Ata... Brasília, DF: Banco Central do Brasil, mar. 2001 a.

. Notas da $58^{a}$ reunião do comitê de política monetária do banco central do Brasil (COPOM). In: REUNIÃO DO COMITÊ DE POLÍTICA MONETÁRIA DO BANCO CENTRAL DO BRASIL, 58., 2001, Brasília, DF. Ata... Brasília, DF: Banco Central do Brasil, abr. 2001b.

. Notas da $60^{a}$ reunião do comitê de política monetária do banco central do Brasil (COPOM). In: REUNIÃO DO COMITÊ DE POLÍTICA MONETÁRIA DO BANCO CENTRAL DO BRASIL, 60., 2001, Brasília, DF. Ata... Brasília, DF: Banco Central do Brasil, jun. 2001c. 
. Notas da $76^{a}$ reunião do comitê de política monetária do banco central do Brasil (COPOM). In: REUNIÃO DO COMITÊ DE POLÍTICA MONETÁRIA DO BANCO CENTRAL DO BRASIL, 76., 2002, Brasília, DF. Ata... Brasília, DF: Banco Central do Brasil, out. 2002. set. 2007.

Política monetária e defasagens do mecanismo de transmissão. Relatório de Inflação,

Taxa de poupança familiar: uma análise regional. Boletim Regional do Banco Central do Brasil, jan. 2013.

BATINI, N.; HALDANE, A. Forward-looking rules for monetary policy. In: TAYLOR, J. B. (Ed.). Monetary policy rules. Chicago: University of Chicago Press, 1999. p. 157-192.

BAXTER, M.; KING, R. Measuring business cycles: approximate band-pass filters for economic time series. Review of Economics and Statistics, v. 81, n. 4, p. 575-593, 1999.

BERNANKE, B.; GERTLER, M. Monetary policy and asset price volatility. Federal Reserve Bank of Kansas City Economic Review, Fourth Quarter, p. 18-51, 1999.

. Should central banks respond to movements in asset prices? American Economic Review, v. 91, n. 2, p. 253-257, 2001.

BJÖRLAND, H. C.; LEITEMO, K. Identifying the interdependence between US monetary policy and the stock market. Journal of Monetary Economics, v. 56, n. 2, p. 275-282, 2009.

BORDO, M. D.; JEANNE, O. Monetary policy and asset prices: does 'benign neglect' make sense? International Finance, v. 5, n. 2, p. 139-164, 2002.

BORGES FILHO, J. P. Regra de Taylor no Brasil e preços de ativos financeiros: 1999-2005. 2006. 34 f. Dissertação (Mestrado em Economia) - Fundação Getúlio Vargas, Rio de Janeiro, 2006.

BORIO, C.; KENNEDY, N.; PROWSE, S. D. Exploring aggregate asset price fluctuation across countries: measurement, determinants and monetary policy implications. Basel: Bank for International Settlements, 1994. (BIS Working paper, n. 40).

BORIO, C.; LOWE, P. Asset prices, financial and monetary stability: exploring the nexus. Basel: Bank for International Settlements, 2002. (BIS Working paper, n. 114).

BOTZEN, W.; MAREY, P. Did the ECB respond to the stock market before the crisis? Journal of Policy Modeling, v. 32, n. 3, p. 303-322, 2010.

CALVO, G.; REINHART, C. Fear of floating. Quarterly Journal of Economics, v. 117, n. 2, p. 379-408, 2002.

CARVALHO, F. A.; MINELLA, A. Survey forecasts in Brazil: a prismatic assessment of epidemiology, performance, and determinants. Journal of International Money and Finance, v. 31, n. 6, p. 1371-1391, 2012.

CECCHETTI, S. G. et al. Asset prices and central bank policy. Geneva: Geneva Reports on the World Economy, 2000. 
CECCHETTI, S.; GENBERG, H.; WADHWANI, S. Asset prices in a flexible inflation targeting framework. In: HUNTER, W.; KAUFMAN, G; POMERLEANO, M. (Ed.). Asset price bubbles: the implications for monetary, regulatory, and international policies. Cambridge: MIT Press, 2003.

CHRISTIANO, L.; FITZGERALD, T. The band pass filter. International Economic Review, v. 44, n. 2, p. 1-31, 2003.

CLARIDA, R.; GALÍ, J.; GERTLER, M. Monetary policy rules in practice: some international evidence. European Economic Review, v. 42, n. 6, p. 1033-1067, 1998.

COGLEY, T.; NASON, J. Effects of the Hodrick-Prescott filter on trend and difference stationary time series-implications for business cycle research. Journal of Economic Dynamics and Control, v. 19, n. 1-2, p. 253-278, 1995.

DANNE, C.; SCHNABL, G. A role model for China? Exchange rate flexibility and monetary policy in Japan. China Economic Review, v. 19, n. 2, p. 183-196, 2008.

DUPOR, B.; CONLEY, T. The FED response to equity prices and inflation. American Economic Review, v. 94, n. 2, p. 24-28, 2004.

FUHRER, J.; TOOTELL, G. Eyes on the prize: how did the Fed respond to the stock market? Journal of Monetary Economics, v. 55, n. 4, p. 796-805, 2008.

FURLANI, L. G. C.; PORTUGAL, M. S.; LAURINI, M. P. Exchange rate movements and monetary policy in Brazil: econometric and simulation evidence. Economic Modelling, v. 27, n. 1, p. 284-295, 2010.

GOODFRIEND, M. Interest rates and the conduct of monetary policy. Carnegie-Rochester Series on Public Policy, v. 34, n. 1, p. 7-30, 1991.

GRANGER, C. The typical spectral shape of an economic variable. Econometrica, v. 34, n. 1, p. 150-161, 1966.

GREENE, W. H. Econometric Analysis. 5. ed. New Jersey: Prentice Hall, 2003.

HANSEN, L. P. Large sample properties of generalized method of moments estimators. Econometrica, v. 50, n. 4, p. 129-1054, 1982.

HAUSMANN, R.; UGO P.; ERNESTO, S. Why do countries float the way they float? Journal of Development Economics, v. 66, n. 2, p. 387-414, 2001.

HAYFORD, M. D.; MALLIARIS, A. How did the Fed react to the 1990s stock market bubble? Evidence from an extended Taylor rule. European Journal of Operational Research, v. 163, n. 1, p. 20-29, 2005.

HOFFMANN, A. Did the ECB react asymetrically with respect to asset market developments? Journal of Policy Modeling, v. 35, n. 2, p. 197-211, 2013.

HSIAO, C. Cointegration and dynamic simultaneous equations models. Econometrica, v. 65, n. 3, p. 358-398, 1997a. 
. Statistical properties of the two-stage last squares estimator under cointegration. The $\overline{\text { Review }}$ of Economic Studies, v. 64, n. 3, p. 647-670, 1997b.

ISSING, O. Asset prices and monetary policy. The Cato Journal, v. 29, n. 1, p. 45-51, 2009.

. Lessons for monetary policy: what should the consensus be? Dallas: Federal Reserve Bank of Dalla Globalization and Monetary Policy Institute, 2011. (Working paper, n. 81).

KANNAN, P.; RABANAL, P.; SCOTT, A. Monetary and macroprudential policy rules in amodel with house price booms. The B.E. Journal of Macroeconomics, v. 12, n. 1, p. 1-42, 2012.

KING, R.; REBELO, S. Low-frequency filtering and real business cycles. Journal of Economic Dynamics and Control, v. 17, n. 1-2, p. 207-231, 1993.

KLEIN, J. K. Preços de ativos e determinação da política monetária brasileira: uma análise empírica. 2007. 46 f. Dissertação (Mestrado em Economia) - Departamento de Economia, Pontifícia Universidade Católica do Rio de Janeiro, Rio de Janeiro, 2007.

LUBIK, T. A.; SCHORFHEIDE, F. Do central banks respond to exchange rate movements? A structural investigation. Journal of Monetary Economics, v. 54, n. 4, p. 1069-1087, 2007.

MELLO, L.; MOCCERO, D. Monetary policy and inflation expectations in Latin America: long-run effects and volatility spillovers. Journal of Money, Credit and Banking, v. 41, n. 8, p. 1671-1690, 2009.

MINELLA, A. et al. Inflation targeting in Brazil: constructing credibility under Exchange rate volatility. Journal of International Money and Finance, v. 22, n. 7, p. 1015-1040, 2003.

MINELLA, A., SOUZA-SOBRINHO, N. Monetary policy channels in Brazil through the lens of a semi-structural model. Economic Modeling, v. 61, n. 12, p. 405-419, 2013.

MISHKIN F. How should we respond to asset price bubbles? Philadelphia: Speech Held at the Wharton Financial Institutions Center, 2008.

. Housing and the monetary transmission mechanism. Cambridge: National Bureau of Economic Research, 2007. (NBER Working Paper, n. 13518).

MOHANTY, M. S.; KLAU, M. Monetary policy rules in emerging market economies: issues and evidence. Basel: Bank for International Settlements, 2004. (BIS Working Paper, n. 149).

MOURA, M. L.; CARVALHO, A. What can Taylor rules say about monetary policy in Latin America? Journal of Macroeconomics, v. 32, n. 1, p. 392-404, 2010.

OSTRY, J. D.; GHOSH, A. R.; CHAMON, M. Two targets, two instruments: monetary and exchange rate policies in emerging market economies. Washington, DC: International Monetary Fund, 2012. (IMF Staff Discussion Note, n. 12/01).

RAVN, M.; UHLIG, H. On adjusting the Hodrick-Prescott filter for the frequency of observations. Review of Economics and Statistics, v. 84, n. 2, p. 371-376, 2002. 
RAVN, S. H. Has the fed reacted asymmetrically to stock prices? The BE Journal of Macroeconomics, v. 12, n. 1, p. 1-34, 2012.

RIGOBON, R.; SACK, B. Measuring the reaction of monetary policy to the stock market. The Quarterly Journal of Economics, v. 118, n. 2, p. 639-669, 2003.

RUDEBUSCH, G. D. Federal reserve interest rate targeting, rational expectations, and the term structure. Journal of Monetary Economics, v. 35, n. 2, p. 245-274, 1995.

SACK, B. Does the fed act gradually? A VAR analysis. Journal of Monetary Economics, v. 46, n. 1, p. 229-256, 2000.

SÁNCHEZ-FUNG, J.R. Estimating monetary policy reaction functions for emerging market economies: The case of Brazil. Economic Modelling, v. 28, n. 4, p. 1730-1738, 2011.

SOARES, J. J. S.; BARBOSA, F. H. Regra de Taylor no Brasil: 1999-2005. In: ENCONTRO NACIONAL DE ECONOMIA, 34., 2006, Salvador. Anais... Salvador: ANPEC, 2006.

SOUZA-SOBRINHO, N. F. Macroeconomics of bank interest spreads: evidence for Brazil. Annals of Finance, v. 6, n. 1, p. 1-32, 2010.

STOCK, J. H.; YOGO, M. Testing for weak instruments in linear IV regression. In: ANDREWS, D. W.; STOCK, J. H (Ed.). Identification and inference for econometric models: essays in honor of Thomas Rothenberg. Cambridge: Cambridge University Press, 2005.

TAYLOR, J. Discretion versus policy rules in practice. Carnegie-Rochester Conference Series on Public Policy, v. 39, p. 195-214, 1993.

Recebido em: 21/12/2015. Aceito em: 31/05/2016. 